EGU2020-7448

https://doi.org/10.5194/egusphere-egu2020-7448

EGU General Assembly 2020

(c) Author(s) 2021. This work is distributed under

the Creative Commons Attribution 4.0 License.

\title{
GEOPHYSICAL MEASUREMENTS IN AN ABANDONED OLD RAILWAY TUNNEL (MARSICO NUOVO, Italy)
}

\author{
Gregory De Martino ${ }^{1}$, Luigi Capozzoli ${ }^{1,2}$, Valeria Giampaolo ${ }^{1}$, and Enzo Rizzo ${ }^{1,3}$ \\ ${ }^{1}$ National Research Council of Italy, Institute of Methodologies for Environmental Analysis, I-85050, Tito Scalo, Italy \\ ${ }^{2}$ National Research Council of Italy, Institute for Electromagnetic Sensing of the Environment, I-80124, Naples, Italy \\ ${ }^{3}$ Dipartimento di Scienze e Fisica della Terra, Università di Ferrara
}

In Europe, there are many abandoned railway tunnels. These structures are generally placed in mountainous or hardly accessible territories, where their use was no longer necessary for the improvement of the road communications and the favourite use of the private car. However, in some cases, they could be an important point of observation to monitor the mountains, where important hydrogeological resource are located. This is the case of an old tunnel sited in Marsico Nuovo village, where the rail way "Atena-Marsico Nuovo" was realized in the early 20th century and worked until the in '60. The studied tunnel has a total length of $1229 \mathrm{~m}$ and, from geological point of view, it is located in the carbonate complex of the Maddalena Mountains and is characterized by the presence of stratified and fractured carbonate rocks. In proximity of this structure, there is also an important karstic cave (Castel di Lepre) already subject to geophysical measurements realized in the past [1]. The presence of a tunnel offers an advantageous perspective to monitor the aquifer improving the knowledge of the fluid circulation in a carbonate rock formation [2].

However, no engineering and geotechnical information about the realization of the construction and the geological setting of the area are available. In order to characterize, from an engineering point of view, the correlation between the hydrogeological formation and the engineering structure, several geophysical surveys, based on electric and electromagnetic acquisitions, were carried out along the gallery. The results obtained show the potentialities of the geophysical methods for monitoring and characterizing engineering structures also providing useful and detailed information for the identification of shallower geological structures in the first meters surrounding the tunnel.

References

[1] E. Rizzo, M. Guerriero, E. Gueguen, L. Capozzoli, G. De Martino and F. Perciante, Cave-surface 
Electrical Resistivity Tomography in "Castello di Lepre" Karst System (Marsico Nuovo, Southern Italy), Monitoring and Characterization of the Shallow Subsurface I, EAGE 2017, DOI: 10.3997/2214-4609.201702078;

[2] M. Guerriero, L. Capozzoli, G. De Martino, V. Giampaolo, E. Rizzo, F. Canora and F. Sdao, Geophysical techniques for monitoring carbonate karstic rocks (2019), Italian Journal of Engineering Geology and Environment, DOI: 10.4408/JJEGE.2019-01.S-10; Project: Landslide Risk Assessment along roads (LaRIS), Special Issue 1 (2019) Sapienza Università Editrice. 